Revista lus et Praxis, Año 23, No 1, 2017, pp. 15 - 18

ISSN 0717 - 2877

Universidad de Talca - Facultad de Ciencias Jurídicas y Sociales

"Editorial"

¿Rigor formal o formalismo exacerbado? Reflexiones a propósito

de los procedimientos editoriales en el mundo jurídico

\title{
EDITORIAL \\ ¿Rigor formal o fORMalismo eXacerbado? ReflexiOnes a Propósito \\ DE LOS PROCEDIMIENTOS EDITORIALES EN EL MUNDO JURÍDICO
}

En el ámbito jurídico en el que nos desenvolvemos estamos acostumbrados a desarrollarnos en el marco del rigor formal. Efectivamente, somos víctimas de aquél durante toda nuestra formación académica y aprendemos, muchas veces a golpe de mala calificación, que las actuaciones bajo determinadas circunstancias precluyen y que la fatalidad de los plazos se encarga de hacer el resto. Como ejemplo paradigmático, nunca nos cansamos de transmitirle a los alumnos que deberán concurrir tempranamente a la Corte y que en la ausencia de respuesta ante un Ilamado formal serán muy excepcionales las circunstancias que les permitan realizar, de todos modos, aquel acto que pretendían.

Por decirlo de algún modo, forma parte de la esencia, del $A D N$, del jurista apegarse a la literalidad de las instrucciones con el objeto de que sus pretensiones no sean vencidas por un incumplimiento formal que evite, siquiera, entrar a debatir quién tiene la razón sino la verdad del asunto sometido a consideración de un órgano jurisdiccional o administrativo, o de la naturaleza que corresponda en cada caso.

Sin embargo, en este contexto, es de suyo señalar que con el paso de los siglos la racionalidad del ser humano ha abogado por eliminar el formalismo exacerbado propio del solemnis ordo iudiciorum, para tratar de llegar a develar los entresijos del asunto de relevancia jurídica sometida a conocimiento, por sobre su exacta vía de consecución. En otras palabras, debemos cuidar, fomentar, reivindicar e incluso proteger el rigor formal, pero no puede cruzarse la línea que lo separa del formalismo exacerbado que, en sí mismo, no es guardián de ningún valor que amerite tutela jurídica.

Ejemplos sobran en nuestra práctica forense y al no ser éste el lugar adecuado para dar cuenta científica de ello, sólo enunciaré un contexto que parece resultar un auténtico hecho notorio. El recurso de nulidad (sea en su ámbito penal, bien sea en el laboral) se ha ido erigiendo como una instancia de exigencia de requisitos que parecen más bien barreras de ejercicio, solamente instauradas con el objetivo de descargar al sistema de asuntos, sin más objetivos que el eficientismo ingenieril. Hay motivos de inadmisión que parecen poco sustentables y -les confieso- que mi favorito es aquel que reivindica el carácter de 
"derecho estricto" como si aquella característica permitiera ejercer un filtro de acceso serio y motivado.

Esta lucha por desterrar nuevos formalismos no debe distraerse. De lo contrario, podemos caer en supuestos de intoxicación cruzada en que, especialmente las Cortes de Apelaciones, se realizan controles de admisibilidad en el orden más laxo (civil) como si se tratara de aquellos impasables filtros de nulidad. Así, recientemente la Corte Suprema (rol № 83347-2016, de 8 de mayo de 2017) ha tenido que intervenir para señalar que la interposición conjunta de los recursos de casación en la forma y apelación, en rigor, no está sometida a un orden legal y, por tanto, no puede inadmitirse su interposición porque se formalizó en el mismo escrito en primer lugar la apelación. Junto con ello debiéramos añadir que, probablemente, no le corresponde al órgano jurisdiccional comprobar aquella circunstancia. Todo lo que nos conduce a reafirmar que un hito tan importante, como el derecho al recurso, no puede ser conculcado por una interpretación que contenga un grado tan elevado de rigurosidad que nos lleve a tildarla de formalismo exacerbado.

Estando claro el punto, aparentemente al menos, esta misma reflexión pretendemos trasladarla al quehacer editorial. La Revista lus et Praxis solicita a sus colaboradores (autores) que se ciñan a una serie de normas que son de fácil consulta en nuestra página web, así como en el ejemplar en papel, en su caso. El sentido común dictamina que cuando se somete un artículo, ensayo o comentario de jurisprudencia a la consideración de la publicación debieran cumplirse con los estándares expresados. Sin embargo, se nos plantean varios interrogantes y mediante esta editorial les vamos a informar de cómo trabajamos en la cotidianidad este tema.

Es formalismo exacerbado revisar todas y cada una de las notas al pie y encontrando una que "olvidó" una coma devolver el original a su autor indicando que no cumple con las normas. Esta es una situación compleja y debe ser transparentada. En los tiempos que corren, lo cierto es que la comunidad jurídico-científica chilena sabe bien lo complicado que está resultando obtener una publicación en una revista indexada en Scopus, que de algún modo se ha convertido en el indicador más importante por el que nos miden. Pues bien, tras un trabajo científico serio, no parece lo más oportuno descargar el trabajo de la publicación con un simple venga en forma.

Hoy en día el autor merece recuperar el respeto que siempre ha tenido. No estamos proponiendo que no se cumplan las normas que nosotros mismos les hemos impuesto, sino que les estamos haciendo saber que con un cumplimiento "promedio" su artículo será arbitrado. Si su contribución no guarda ni el más mínimo parecido con lo dispuesto en nuestros registros, lo más probable es que sea devuelto de inmediato. Pero no rechazaremos un envío porque la fuente que 
usó no era la adecuada, o porque contrastado con nuestro estándar su original no respetó el uso de la cursiva: le pediremos aquellos ajustes necesarios, si es que finalmente su artículo cuenta con el informe favorable del Equipo Editorial.

Todo trabajo merece ser enviado a un proceso de arbitraje siempre que se haya hecho con rigurosidad y profesionalismo. Del mismo modo que un recurso fundado y lleno de razones, un original que aspira a ser publicado debe ser conocido por un Comité Editorial que, al menos, tiene a la vista dos arbitrajes para tomar la compleja decisión de aprobar aquellos textos que contribuyen al desarrollo de la ciencia.

Para esta compleja tarea el equipo de lus et Praxis agradece la labor que durante estos años ha prestado el profesor Dr. Raúl Carnevali Rodríguez como subdirector de la publicación, puesto que asume el desafío de convertirse en el Decano de la Facultad de Ciencias Jurídicas y Sociales de la Universidad de Talca y, adicionalmente, aprovechamos la ocasión para darle la más cordial bienvenida en esas labores al profesor Dr. Diego Palomo Vélez, quien siendo un experto en el mundo editorial del Derecho se suma a este modo de conducir la Revista, con un destacado rigor formal que destierre en sus prácticas cualquier viso de formalismo exacerbado.

Sólo resta invitarlos a explorar con detenimiento los rigurosos originales que en esta ocasión podemos ofrecerles.

\author{
Dr. Jordi Delgado Castro \\ EDitor EN JEFE
}

